\title{
A MODERNIZAÇÃo DO DIREITO DO TRABALHO
}

\author{
Otávio Pinto e Silva \\ Professor Assistente do Departamento de Direito do \\ Trabalho da Faculdade de Direito da Universidade de \\ São Paulo
}

\begin{abstract}
Resumo:
As transformações econômicas do final do século $\mathrm{XX}$ levam à necessidade de modernização do Direito do Trabalho. Esse ramo do Direito deve se adaptar à uma nova realidade, em que as inovações tecnológicas e a competitividade do mercado exigem mudanças nas relaçōes entre trabalhadores e empresários. Mostram-se imprescindíveis, assim, a revisão do sistema brasileiro de organização sindical, o incremento da contratação coletiva e a formulação de um novo papel para o Estado.
\end{abstract}

\begin{abstract}
:
The economic changes at the end of the twentieth century lead to the need for the modernization of Labor Law. This kind of Law must be adapted to a new reality in which the technological innovations and the market competitiveness demand changes in the relations between employees and enterprises. Therefore, the revision of the Brazilian system of union organization, the increase of collective contracts and the creation of a new role for the State are indispensable.
\end{abstract}

Unitermos: Direito do Trabalho; Direito Sindical; contratação coletiva.

\section{Introdução}

Este final de século já está marcado como um momento histórico de profundas transformações econômicas, consubstanciadas em diversas medidas governamentais relacionadas com a abertura comercial, a redução do tamanho do Estado, a privatização de determinados serviços públicos, a revitalização do livre jogo de mercado e a chamada "globalização" ou "mundialização" da economia.

O capitalismo entra em uma nova fase e, nesse contexto, aparece como conseqüência a demanda por uma "flexibilização do Direito do Trabalho", explicada por Cássio Mesquita Barros Jr. como a possibilidade de oferecer mecanismos 
jurídicos que permitam às empresas ajustes da produção, do emprego e das condições de trabalho tendo em vista as flutuações rápidas e contínuas do sistema econômico. ${ }^{1}$

O quadro legal e constitucional brasileiro necessita passar por alterações para que o Direito do Trabalho possa se modernizar, acompanhando todas as importantes transformações políticas e econômicas.

$\mathrm{O}$ atual sistema brasileiro de relações de trabalho caracteriza-se por: a. uma organização sindical que contém restrições à liberdade e autonomia sindical; $b$. um processo de negociação coletiva atrofiado pela sua própria estrutura e pela atuação do Poder Judiciário (especialmente na solução dos conflitos coletivos de trabalho); c. uma excessiva intervenção do Estado (Poderes Legislativo e Executivo) na criação das normas de Direito do Trabalho, em detrimento da participação dos interessados (trabalhadores e empregadores).

Para a adoção de um novo sistema, que privilegie a contratação coletiva como fonte do Direito do Trabalho, é imprescindível uma radical transformação institucional, que atinja todos os pontos acima e que se fundamente em um princípio estabelecido na própria Constituição: a democracia pluralista. ${ }^{2}$

Isso implica mudanças no texto constitucional, na legislação do trabalho e no próprio comportamento da sociedade, fundadas principalmente em medidas que venham a redefinir: a. o sistema de organização sindical; b. o processo de negociação coletiva; c. o papel do Estado.

É necessário frisar que o sistema político em que foi gerado e consolidado o sistema brasileiro de relações de trabalho caracterizou-se pelo autoritarismo. A Constituição de 1988 melhorou o quadro em alguns aspectos, mas infelizmente manteve a essência de um modelo que hoje já se mostra ultrapassado.

Vejamos, então, as principais medidas modernizadoras que se fazem necessárias.

1. Barros Jr., Cássio de Mesquita. Flexibilização do Direito do Trabalho. São Paulo, Revista LTr, v. 59, agosto de 1995, pp. 1.034-1.045.

2. O pluralismo consagrado no art. $1^{\circ}$, inciso V, da Constituição Federal, significando obviamente não apenas pluralidade partidária, mas também religiosa, ideológica, sindical, política. 
2. Quanto à organização sindical

As transformações propugnadas devem começar pela organização sindical e representação dos trabalhadores no local de trabalho.

A primeira das medidas reformadoras é a supressão da regra da unicidade sindical, prevista no art. $8^{\circ}$, inciso II, da Constituição Federal. Como destaca Octavio Bueno Magano, hoje em dia a idéia da unicidade sindical está superada, pois parte de um pressuposto verdadeiro na época em que surgiu, mas presentemente falso, qual seja, "o de que as categorias e as profissões devem estar identificadas com a visão unitária do Estado a respeito da economia. Tal visão se mostra incompativel com as diretrizes de uma sociedade democrática e pluralista. ${ }^{3}$

Os parâmetros para a organização sindical devem ser os estabelecidos pela Convenção 87 da Organização Internacional do Trabalho (OIT), consagrandose os princípios da liberdade e autonomia sindical que, em última análise, servem para gerar sindicatos legítimos e representativos.

Cabe aos interessados trabalhadores e empregadores - definir quantas e quais entidades representarão seus interesses, pois a unidade do movimento sindical não deve ser imposta mediante intervenção legislativa estatal, que contraria o princípio de liberdade sindical previsto no art. $2^{\circ}$ da referida convenção internacional. A unidade é desejável, mas deve ser uma conquista dos interessados e nunca uma imposição legal.

Uma segunda medida indispensável é a supressão tanto na Constituição (art. $8^{\circ}$. inciso II) quanto na lei (parágrafos do art. 511 da CLT) das referências aos conceitos de categorias econômica, profissional e diferenciada, o que possibilitaria um rearranjo da organização sindical com base nos critérios que melhor se apresentarem aos trabalhadores e empresários, segundo suas conveniências.

Podem até optar pela manutenção, em alguns setores, de divisões das áreas de atuação com critérios semelhantes aos atuais (mantendo-se sindicatos de bancários, metalúrgicos, etc.), mas o importante é que isso resultaria da opção espontânea dos interessados e não da imposição estatal. 
Não deve o Estado estabelecer a forma de organização dos sindicatos, impondo a existência das categorias; ao contrário, deve ser deixada aberta a possibilidade de escolha aos próprios grupos.

A terceira medida de garantia da liberdade e autonomia sindical é a revogação da regra constitucional (também contida no inciso II do art. $8^{\circ}$ ) que prevê a área do município como limite mínimo da base territorial dos sindicatos.

Com isso, abrir-se-ia a possibilidade de criação de sindicatos por empresas ou por região geográfica, em conformidade com a similitude das condições de trabalho nas empresas envolvidas e de acordo com as conveniências e circunstâncias ditadas pelos interesses dos trabalhadores e empregadores.

Essas três primeiras medidas, portanto, representam a aplicação prática do princípio da livre formação de sindicatos, de tal modo que um grupo de trabalhadores ou de empregadores poderá livremente criar uma entidade sindical, sem estar sujeito a atos de ingerência do Poder Público. Poderá ser formado o tipo de sindicato que interessar a tal grupo, não importando a eventual existência de outra entidade na mesma profissão, categoria, empresa, ramo de atividade ou área geográfica. O sindicato não estará sujeito à predeterminação, pelo Poder Público, de seu âmbito de representação, nem da área territorial em que atuará.

A quarta medida sugerida é o fim da contribuição sindical compulsória, que não se justifica em um sistema de pluralidade sindical, uma vez que os trabalhadores e os empresários devem ter o direito de se filiar à organização sindical de sua escolha, com a única condição de se conformarem com os seus estatutos.

$\mathrm{O}$ art: $2^{\circ}$ da Convenção 87 consagra o direito do indivíduo aderir ounão à entidade sindical, isto é, não impõe um dever de sindicaliżação; de tal forma, a obrigação de pagar uma contribuição ao sindicato pressupõe o ato voluntário de filiação.

A liberdade sindical é, portanto, incompatível com a imposição (por via legal ou constitucional) do pagamento da contribuição sindical obrigatória: se a sindicalização é um direito, a contribuição não pode ser uma obrigação. Nesse contexto, mostra-se imprescindível a revogação do inciso IV do art. $8^{\circ}$ da Constituição, bem como de todo o Capítulo III, do Título V, da CLT.

A quinta transformação proposta consiste na criação de novas formas de representação dos trabalhadores no local de trabalho. Aqui, inexiste óbice legal ou constitucional: a questão é cultural e está ligada a uma mudança de mentalidade. 
A idéia é ampliar os canais institucionais de atuação dos trabalhadores, incrementando a sua participação na administração do dia a dia das empresas. Atualmente, já existem mecanismos como a CIPA (Comissão Interna de Prevenção de Acidentes), que, no entanto, têm uma competência restrita às questões de medicina e segurança do trabalho e prevenção de acidentes.

É preciso repensar as formas de representação dos trabalhadores dentro da empresa, criando alternativas aos órgãos sindicais e à CIPA, de maneira a tornarem mais freqüentes as negociações nos próprios locais de trabalho e a democratizar a administração das empresas.

Existem dois dispositivos constitucionais nesse sentido que merecem ser lembrados: o art. 11 (que assegura, nas empresas com mais de duzentos empregados, a eleição de um representante destes com a finalidade exclusiva de promover-lhes o entendimento direto com os empregadores) e o inciso XI do art. $7^{\circ}$ (que prevê a participação dos trabalhadores, em caráter excepcional, na gestão da empresa).

Como bem ressalta Walküre Lopes Ribeiro da Silva, o movimento sindical brasileiro está diante de um desafio, pois as mudanças que foram introduzidas no modelo corporativista já atingiram seus limites. Nas palavras da citada autora, "somente será possível renovar verdadeiramente esse modelo se se romper de vez com o corporativismo, consagrando plena liberdade sindical, o que implica dar nova configuração à organização dos trabalhadores $e$ dos empregadores, tanto no plano externo quanto no plano da empresa'. ${ }^{4}$ Daí, portanto, a importância da criação de novas formas de representação.

\section{Quanto à negociação coletiva}

Para uma efetiva modernização do Direito do Trabalho, é fundamental a criação de um processo livre de negociação coletiva.

Em primeiro lugar, deve ser alterada a regra que dá o monopólio da negociação coletiva aos sindicatos (inciso VI do art. $8^{\circ}$ da Constituição), de modo a efetuar a redefinição de agentes legitimados a negociar e incluir no processo

4. Silva, Walküre Lopes Ribeiro da. Representação e Participaçāo dos Trabalhadores na Gestāo da Empresa, São Paulo, Editora LTr, 1998, p. 181. 
negocial tanto as Centrais Sindicais quanto as representações dos trabalhadores nos locais de trabalho.

Tal alteração pode ser efetuada de duas maneiras: pela supressão pura e simples do inciso VI do art. $8^{\circ}$. da CF (de modo que, na omissão da Constituição, entender-se-ia que qualquer órgão de representação dos trabalhadores está legitimado a negociar), ou pela sua manutenção, mas acrescido da referência a esses novos agentes negociadores.

Com isso, entendo que se abriria a possibilidade de negociação em todos os âmbitos, de todos os tipos, sobre todos os assuntos ligados ao trabalho. As únicas limitações admissíveis devem ser aquelas decorrentes das normas de ordem pública.

Para a efetividade de um processo negocial assim amplo, fundamental é a existência de verdadeira liberdade sindical, nos moldes preconizados no item anterior; mas a educação e conscientização dos trabalhadores é também pressuposto indispensável, pois somente assim os agentes negociadores adquirem verdadeira representatividade.

Surge um problema sério no sistema de pluralidade sindical: a aferição do sindicato mais representativo, apto a efetuar a negociação coletiva e, conseqüentemente, a celebrar os contratos coletivos de trabalho.

A alteração no sistema de organização sindical viria trazer esta questão para o debate, pois tornaria necessária a determinação de critérios claros para a apuração da representatividade das entidades sindicais.

Uma segunda medida que, a meu ver, igualmente serviria para fortalecer a negociação coletiva consiste na previsão de mecanismos de solução voluntária dos conflitos.

A imposição por lei da solução estatal, oriunda do órgão jurisdicional, tende a acomodar as partes negociadoras: diante das dificuldades intrínsecas do próprio processo negocial, os empregadores ou os trabalhadores, cada qual a seu tempo, acabam deixando de lado o esforço para a obtenção da solução de consenso, esperando uma decisão do Judiciário que porventura possa lhes ser favorável.

Caso as próprias partes tenham de eleger conjuntamente o mecanismo para a solução do conflito, certamente se sentirão mais pressionadas a continuar negociando.

Tais mecanismos podem ser públicos ou privados, pouco importa; o que me parece relevante é afastar a compulsoriedade hoje vigente, manifestada na 
obrigação de ambas as partes obedecerem a uma solução imposta coativamente pela Justiça do Trabalho, ao julgar o dissídio coletivo interposto por provocação de apenas uma delas.

A terceira medida relacionada com o incremento da negociação coletiva é a vigência extratemporal dos convênios coletivos. Trata-se de garantir a manutenção dos efeitos jurídicos de um instrumento normativo, mesmo após o término de sua vigência e até que outro seja celebrado, revogando ou modificando a situação anterior.

Tal medida mostra-se necessária em decorrência da adoção dos mecanismos de solução voluntária dos conflitos: suprimindo-se a via compulsória, o efeito da extratemporalidade surge como uma garantia efetiva da negociação. Enquanto não vier a ser obtido um novo acordo, permanecem aplicáveis as normas previstas no anterior.

É uma providência simples, que visa evitar a má-fé no processo negocial (por exemplo: a utilização de subterfúgios para impedir a concretização das negociações e criar lacunas na regulamentação das condições de trabalho, como um desleal instrumento de pressão de uma parte sobre a outra).

Ressalva-se, aqui, a teoria da imprevisão dos contratos, pela aplicação da cláusula "rebus sic stantibus" de modo a eximir as partes de cumprirem o que tiver sido avençado apenas quando houver justificado motivo, decorrente de prejuízos comprovados ou alteração substancial das condições acordadas.

A quarta medida de sustentação da negociação coletiva se refere à garantia do direito de greve, que é fundamental para o equilíbrio de forças no desenrolar do processo negocial.

Nesse aspecto, o texto da Constituição de 1988 é bastante claro, ao prever a greve como um direito dos trabalhadores e ao asseverar que compete a eles decidir sobre a oportunidade de exercê-lo e sobre os interesses que devam por meio dele defender.

Cumpre ressaltar a dificuldade de harmonizar esse direito com outros também constitucionalmente previstos, especialmente quando os movimentos paredistas atingem os chamados serviços essenciais (capazes de causar prejuízos não-somente ao empregador, mas também à sociedade).

No contexto democrático a greve deve ser aceita como um instrumento legítimo e os limites ao seu exercício somente podem ser admitidos quando estiverem em jogo interesses superiores da sociedade. 
A noção básica a trabalhar, fixada pela própria Constituição (art. $9^{\circ}, \S$ $2^{\circ}$ ), é a do abuso de direito, podendo ser enunciada como o princípio da responsabilidade: no exercício do direito de greve, os responsáveis por eventuais abusos devem ser punidos na forma da lei.

A Lei n. 7.783/89 regulamenta a questão de uma forma que deve ser revista, pois exige uma série de formalidades burocráticas para a deflagração dos movimentos grevistas e dispõe, no art. 14, que constitui abuso de direito a simples inobservância das normas nela contidas.

Com isso, os tribunais trabalhistas se especializaram em julgar a "abusividade" de greves, levando em conta a mera desobediência a aspectos formais, o que não me parece correto, pois serve como uma maneira de enfraquecer a posição dos trabalhadores.

No Estado Democrático de Direito, a apuração de eventuais aḅusos de ordem civil, penal e trabalhista, quando do exercício do direito de greve, deve ser efetuada em processos regulares (à luz do contraditório e da ampla defesa), para a punição dos responsáveis, mas nunca para simplesmente forçar os trabalhadores a encerrar uma greve, mesmo que esta esteja causando prejuízos e desconforto.

A responsabilidade civil pelos danos materiais causados é uma forma de reparação do abuso de direito praticado pelo sindicato; a punição penal é um modo de responsabilizar o autor de ilícitos criminais; a dispensa por justa causa é uma sanção trabalhista a que se sujeita o grevista pelos excessos que praticar.

Na arguta visão de Amauri Mascaro Nascimento, "a greve exerce uma pressão necessária que leva à reconstrução do direito do trabalho quando as normas vigentes não atendem às exigências do grupo social. Força o empregador a fazer concessões que não faria de outro modo. Obriga o legislador a se manter vigilante e reformular a ordem jurídica. Logo, apesar dos seus inconvenientes, a greve é necessária e compatível com as estruturas capitalistas'. 5

5. Nascimento, Amauri Mascaro. Curso de Direito do Trabalho, São Paulo, Editora Saraiva, 1992, p. 633. 


\section{Quanto ao papel do Estado}

A redefinição do papel do Estado em um novo modelo de relações de trabalho é algo que se impõe, como decorrência das próprias transformações econômicas vividas pelo mundo contemporâneo.

O excesso de intervencionismo estatal no campo do trabalho hoje é visto como um obstáculo ao desenvolvimento econômico, que precisa ser removido ou - ao menos - ultrapassado.

Mas trata-se de tarefa complexa, pois não se pode admitir o simples retorno aos primórdios da Revolução Industrial (quando em nome do liberalismo pregava-se o total afastamento do Estado das relações contratuais entre trabalhadores e empresários).

A presença estatal é indispensável, porém em bases distintas das que vigoraram até agora.

Já se afirmou que essa redefinição do papel do Estado pode ser efetuada segundo duas concepções diversas: ${ }^{6}$ a. a do "Estado mínimo" isto é, aquele cujas funções seriam progressivamente esvaziadas, por meio da transferência de muitas delas para o mercado e para o setor privado; ou b. a concepção do "Estado regulador" em que não se cogita do esvaziamento das funções estatais, mas sim a sua reestruturação, para fazer frente às exigências das transformações econômicas.

Nessa segunda visão, assume relevância a fixação das funções de "regulação" não-só com referência aos efeitos negativos decorrentes das imperfeições do mercado, mas também num sentido social mais amplo, vinculado às necessidades de legitimação da nova ordem econômica.

Para os defensores da tese do "Estado mínimo". a desregulamentação deve ser a mais abrangente possível, nos mais diversos âmbitos de atividade, repercutindo diretamente nas relações trabalhistas.

Já para os adeptos da teoria do "Estado regulador", o objetivo é substituir as antigas formas de regulação por outras, novas, em harmonia com as metas de produtividade, competitividade e estabilidade econômica.

Essa parece ser a concepção mais adequada, pois conforme acentua Luis Carlos Amorim Robortella, "o Direito do Trabalho cumpriu e continuará a

6. Campero, Guillermo; Flisfisch, Angel; Tironi, Eugenio; Tokman, Victor. Os atores sociais no novo mundo do trabalho. São Paulo-Brasília, Editora LTr-OTT, 1994. 
cumprir a função histórica permanente de assegurar o equilíbrio entre o interesse público, o interesse patronal e o interesse dos trabalhadores. O grande desafio atual está relacionado com a adoção de novas técnicas de proteção, que levem em conta as transformações no mundo do trabalho trazidas pelas novas tecnologias, pelo crescimento do desemprego, pela revalorização do trabalho autônomo, pela magnitude da economia submersa". ${ }^{7}$

Pensando então nas funções que incumbem ao Estado no desempenho desse papel "regulador", vejamos as medidas modernizadoras necessárias.

Em primeiro lugar, há que se manter uma tutela mínima indispensável para a relação de emprego: a modificação estrutural propugnada não chega ao ponto de autorizar a revogação das regras de proteção aos trabalhadores, como já pensam algumas cabeças mais afoitas.

Normas sobre a limitação da jornada de trabalho, os períodos de férias e repouso, o conteúdo do contrato de trabalho, a proteção ao trabalho da mulher e do adolescente, a garantia contra as dispensas imotivadas, a segurança e a medicina do trabalho, são exemplos de matérias que devem ser reguladas na Constituição ou na lei.

Quando se pensa na tutela da relação de emprego há que se lembrar a função histórica do Direito do Trabalho, explicada por Cesarino Jr. como a proteção ao hipossuficiente, efetuada em especial por meio das normas de ordem pública.

A importância dessa noção de tutela aos mais fracos é constatada até mesmo fora do campo do Direito do Trabalho: o desenvolvimento do chamado Direito do Consumidor bem demonstra que o Estado deve necessariamente intervir na vida social para buscar equilibrar as relações jurídicas entre partes desiguais.

Desse modo, a previsão de medidas legais de proteção contra as despedidas arbitrárias ou sem justa causa é um exemplo de matéria que demonstra a importância do papel tutelar do Estado na regulamentação da relação de emprego.

A Convenção 158 da OIT prevê em seu art. $4^{\circ}$ que não se porá fim à relação de trabalho a menos que exista uma causa justificada relacionada com a capacidade ou conduta do trabalhador ou fundamentada nas necessidades de funcionamento da empresa.

7. Robortella, Luis Carlos Amorim. Direito do Trabalho e Proteção dos Direitos Individuais, in $O$ Trabalho no Brasil no limiar do Século XXI, São Paulo, Editora LTr, 1995, pp. 310 e ss. 
Infelizmente, referida norma internacional vigorou por pouco tempo no ordenamento jurídico brasileiro, tendo sido denunciada após acirrados debates quanto à sua constitucionalidade.

Urge, dessa forma, ser elaborada lei complementar que discipline a proteção ao emprego (lei esta esperada desde a promulgação da Constituição, diante do dispositivo contido no art. $7^{\circ}$, inciso I).

A solução transitória imaginada pelo constituinte (pagamento de indenização compensatória da dispensa imotivada, calculada à base de $40 \%$ do valor dos depósitos do FGTS) ${ }^{8}$ já deveria ter sido substituída, pois em verdade é pouco eficaz. A omissão legislativa sobre essa questão é absolutamente injustificável.

Paralelamente, é fundamental que sejam abertos espaços para a negociação coletiva no que se refere à própria aplicação do Direito, permitindo-se alternativas de execução que não o desnaturem.

A adoção de normas trabalhistas mais flexíveis, criadas por meio da negociação coletiva, poderá servir para estancar o progressivo processo de marginalização do trabalhador brasileiro: pesquisa de âmbito nacional divulgada pelo IBGE, em março de 1996, demonstra que a informalidade está crescendo no mercado de trabalho do Brasil. ${ }^{9} \mathrm{O}$ número de trabalhadores com registro em carteira vem caindo e em conseqüência diminui também o número de contribuintes para a Previdência Social.

Não se pode negar que a rigidez do modelo brasileiro de relações de trabalho é uma das causas da existência dessa imensa economia informal, caracterizada pela inserção de trabalhadores em precários postos de trabalho ("camelôs" "marreteiros" autônomos) ou na pura clandestinidade (empregados sem registro na carteira de trabalho, falsos autônomos).

O combate à economia informal é também uma função do Estado, para atacar esse injusto processo de marginalização dos trabalhadores. Várias técnicas podem ser adotadas para atingir esse objetivo, como a redução dos encargos sociais incidentes sobre as folhas de salários, o tratamento legislativo diferenciado para as micro, pequenas e médias empresas, o desenvolvimento de políticas de pleno emprego.

8. Art. 10, inciso I, do Ato das Disposições Constitucionais Transitórias.

9. Folha de S. Paulo, 21 de março de 1996, pp. 1-4. 
A realidade demonstra que a simples inserção de um grande número de direitos trabalhistas na Constituição ou na lei não-basta, por si-só, para garantir a tutela aos trabalhadores: é indispensável que estes tenham acesso a tais direitos, o que só é possível mediante a contratação formal, no mercado de trabalho regular.

O debate sobre a economia informal, dessa maneira, passa pela necessária mudança da estrutura legal, pois é insuportável essa divisão dos operadores do mundo do trabalho em "incluídos" e "excluídos" ou "formais" e "informais"

Sendo assim, justifica-se a proposta de tratamento legislativo diferenciado para as empresas, em conformidade com suas próprias dimensões. Parece-me claro que uma microempresa que tenha postos de trabalho para duas ou três pessoas não pode receber da lei o mesmo tratamento que uma grande empresa, capaz de empregar dois ou três milhares de trabalhadores; entretanto, no atual sistema muitos encargos sociais (incidentes sobre as folhas de salários) são os mesmos para ambos os casos!

Ressalte-se que o significado da expressão "encargos sociais" a meu ver, está relacionado apenas com o custo externo do trabalho, vale dizer: não se pode incluir no conceito aqueles valores que são pagos diretamente ao trabalhador (férias, feriados, descansos semanais remunerados, $13^{\circ}$ salário, etc.), mas apenas os referentes às contribuições compulsórias que são devidas pelas empresas, pelo fato de manter uma relação de emprego (por exemplo: Previdência, acidentes de trabalho, FGTS, Incra, Sesi, Senai, Sebrae, etc.).

Dessa maneira, entendo que é perfeitamente admissível, por exemplo, instituir uma maior variação no percentual da contribuição previdenciária, levando em conta a capacidade contributiva de cada empresa. Pode-se cogitar até mesmo de percentuais diversos do FGTS, sempre considerando o tamanho da empresa e a sua força econômica; ou, ainda, distinção também no que se refere à contribuição contra os acidentes de trabalho, tomando-se por base o maior ou menor risco existente na atividade desenvolvida.

Com a redução do custo do trabalho, igualmente diminui o atrativo econômico representado pela clandestinidade, isto é, pela contratação à margem da lei, na informalidade.

É inegável o fato de que o fenômeno da "economia informal" possui contornos sociológicos: o trabalhador aceita trabalhar sem registro, porque precisa 
garantir sua subsistência; o empregador contrata sem registro, porque assim gasta menos. Os interesses são diversos, mas acabam se conjugando.

Outra medida indispensável para a reformulação do sistema brasileiro de relações de trabalho está ligada à necessidade de previsão de mecanismos mais efetivos de proteção contra os atos anti-sindicais.

É imprescindível garantir a efetividade da ação sindical durante o processo de negociação coletiva e isso pressupõe não-somente que o Estado impeça as práticas desleais do empregador, mas que também garanta mecanismos reparatórios, ou seja, mecanismos que permitam recompor determinadas situações de fato.

Faz-se necessário, ainda, o incremento da fiscalização trabalhista, de modo a garantir que o Direito do Trabalho seja efetivamente observado no dia a dia. Essa fiscalização deve ser efetuada não-só para preservar os dispositivos legais de tutela do trabalhador (como, por exemplo, os relativos à medicina e à segurança do trabalho), mas também para assegurar o cumprimento das normas contidas nos convênios coletivos de trabalho.

Para atingir esse objetivo, é preciso valorizar a inspeção do trabalho, dotando-a de maiores recursos econômicos e multiplicando o número de fiscais. Mas é fundamental, ainda, estimular a colaboração dos sindicatos de trabalhadores com o Poder Público, visando atuação conjunta no trabalho fiscalizatório, consoante destaca Nelson Mannrich. ${ }^{10}$

$\mathrm{Na}$ visão do citado autor, nos últimos anos vem acontecendo em diversos países um esforço de simplificação e unificação de todas as normas de segurança e medicina do trabalho, com a consciência de que não-basta legislar a fim de reduzir ou eliminar os riscos profissionais do trabalho.

O objetivo a alcançar é um sistema que dê preferência à prevenção, mas de uma forma equilibrada: afinal, havendo um excesso de leis nessa área, correse o risco de não serem cumpridas, enquanto por outro lado a insuficiência delas pode levar ao abuso. Em ambas as hipóteses, o que se verifica é o descrédito do Direito como meio de proteção do trabalhador.

Sendo assim, Mannrich propugna a necessidade de um mínimo de legislação, que deve ser complementada por normas coletivas e adaptada aos 
diversos locais de trabalho, o que implica a participação dos trabalhadores tanto na criação das regras de proteção quanto na fiscalização do seu cumprimento.

Outro campo que também deve ser objeto de medidas reformadoras é o da Justiça do Trabalho, impondo-se, em primeiro lugar, o fim do seu poder normativo. Considerando a já propugnada adoção de mecanismos voluntários de solução dos conflitos, não se justifica a manutenção do poder normativo, uma vez que esse é um fator de inibição na efetividade da negociação coletiva.

Dessa maneira, há de ser alterado o $\S 2^{\circ}$ do art. 114 da Constituição Federal para extinguir a figura dos dissídios coletivos de natureza econômica. Importa impedir que uma das partes, por sua exclusiva iniciativa, possa provocar um órgão jurisdicional para impor uma solução.

Isso não-significa desprezar a experiência já acumulada pelos grupos normativos dos diversos TRT's espalhados pelo Brasil, que talvez pudessem continuar a funcionar, mas com uma outra dimensão: a de órgãos de arbitragem pública, aos quais as partes somente poderiam recorrer de comum acordo, aceitando de livre e espontânea vontade a submissão ao laudo arbitral.

A criação de serviços públicos de mediação e arbitragem é, portanto, outra medida modernizadora, que viria preencher essa necessidade de composição dos conflitos trabalhistas sem o caráter de compulsoriedade.

Note-se que essa alteração não seria apenas cosmética, uma vez que a solução dos conflitos por meio desses órgãos somente ocorreria quando os próprios atores sociais se dispusessem a tanto.

Nenhum deles poderia, sozinho, exigir a intervenção de outrem para a resolução da controvérsia, o que certamente serviria para comprometer as partes com a negociação.

Por fim, ainda no campo da Justiça do Trabalho, é necessário rever a composição dos seus órgãos: a supressão da representação classista é uma medida indispensável para o efetivo rompimento com o sistema corporativista (o que exige a reforma dos arts. 111, 113, 115, 116 e 117 da Constituição Federal).

\section{Conclusão}

A modernização do Direito do Trabalho é uma necessidade imperiosa, diante das intensas transformações vividas nas relações de trabalho. A conjuntura 
internacional mostra uma crescente busca do aumento da produtividade das empresas, em face da concorrência cada vez mais acentuada.

As inovações tecnológicas servem a esse propósito de aumento da produtividade, mas têm um efeito perverso, pois em muitos setores levam à redução do número de postos de trabalho. Não há dúvida de que o desemprego é um dos mais graves problemas contemporâneos, decorrente justamente dessa situação.

Ocorre que as empresas não podem deixar de adotar tais inovações, sob pena de ficarem para trás na disputa pelos mercados. Sendo assim, pode-se dizer que o Direito do Trabalho no limiar do século XXI entra em uma nova fase, necessitando passar por medidas modernizadoras que atendam aos interesses dos trabalhadores, mas também dos empresários.

De nada adianta uma legislação trabalhista detalhada e garantidora de inúmeros direitos, quando cada vez menos trabalhadores têm acesso a ela.

O momento é de adaptação a uma nova realidade internacional, que passa, portanto, pela reorganização sindical e pelo incremento da contratação coletiva, cabendo ao Estado importantíssimo papel regulador.

São Paulo, janeiro de 1999.

Bibliografia

BARROS JR., Cássio de Mesquita. Flexibilização do Direito do Trabalho. São Paulo, Revista LTr, v. 59, agosto de 1995.

CAMPERO, Guillermo; FLISFISCH, Angel; TIRONI, Eugenio; TOKMAN, Victor. Os atores sociais no novo mundo do trabalho. São Paulo-Brasília, Editora LTr-OIT, 1994.

MAGANO, Octavio Bueno. Manual de Direito do Trabalho. São Paulo, Editora LTr, 1993.

MANNRICH, Nelson. Inspeção do Trabalho. São Paulo, Editora LTr, 1991.

NASCIMENTO, Amauri Mascaro. Curso de Direito do Trabalho, São Paulo, Editora Saraiva, 1992.

ROBORTELlA, Luis Carlos Amorim. Direito do Trabalho e Proteção dos Direitos Individuais, in O Trabalho no Brasil no limiar do Século XXI. São Paulo, Editora LTr, 1995. 
SILVA, Walküre Lopes Ribeiro da. Representação e Participação dos Trabalhadores na Gestão da Empresa, São Paulo, Editora LTr, 1998. 